\title{
They deserved better
}

$\mathrm{T}$ he irony is almost palpable. At a time when the World Health Organization is seeking to develop a measure of international standardization of principles and standards for organ transplantation, our organ donation policies and programs are mired in what Canadian Society for Transplantation President Lori West once called the "eternal divide" of intergovernmental jurisdictional wrangling ( $C M A J$ 2006;175:I043-4). Rather than a rational, national system for equitably allocating available organs and optimizing donations, Canada's fractured jurisdiction over health care has yielded a quintessential hodgepodge of provincial policies, practices and systems.

Opponents of national approaches argue the widespread variations are desirable because they reflect the supposedly differing needs of the populace in each of ro provinces and 3 territories. Yet, the harsh reality is that ordinary Canadians in all the provinces and territories pay the price for such political posturing on a daily basis. Nearly 4000 of them now anxiously wring their hands as they sit on waiting lists, praying for the call that tells them an organ has become available.

A study recently published in $C M A J$ indicated that people under 40 waited a median 8 years in Ontario for a new kidney, compared with 3 years in Alberta (CMAJ 2006;175:478-82). The nation's crude donation rate for deceased donors was a meager I2.8 per million in 2005, well behind that of countries like Spain (35.I), Estonia (26.5), Belgium (22.8), the United States (2I.5) and Italy (20.9).

Meanwhile, some 275 Canadians died waiting in 2005.

They deserved better.

And we can do better.

To that end, we need a national registry and mechanism for allocating organs to ensure equity of access. We need a national oversight agency to optimize donor recruitment by developing and implementing national strategies to improve organ donation rates, to standardize organ donation and management practices, and to promote sharing of best practices within Canada and internationally.

Those are hardly radical notions. The United States has had a national registry and allocation mechanism since I984. Their United Network for Organ Sharing maintains nationwide wait lists and oversees mandatory organ sharing for priority patients, in a manner that is considered fair and equitable. Canada lacks all of the above. Given that reality, one wonders why court challenges haven't surfaced from disgruntled patients.

The same checkerboard approach and inertia characterize policies aimed at improving organ donation rates. As a consequence, we do not yet have mandatory nationwide reporting of intensive care unit or emergency department deaths. There's no standardization of policy on definition and determination of brain death. Nor has Canada moved to examine and establish concrete nationwide policies on issues like donation after car- diac death, paired exchange between living donors in different provinces, or incentives like priority access for previous donors who need organs or reimbursing donors for related medical leave, travel and accommodation, and funeral expenses.

Without question, there are enlightened pockets within the disparate Canadian organ-transplant communities, like Ontario's Trillium Gift of Life Network, that are exploring concepts like "first-person consent," under which organs are automatically harvested from the bodies of those who signed donor cards without having to first obtain consent from their grieving families.

Those who are skeptical about the need for national approaches have argued such progressive policies aren't essential, ostensibly because Canada's crude organ donation rate is comparable to that of the average European nation, after factoring in methodological differences in calculating rates.

Yet, even if that's true, surely we can do better than aspire to mediocrity. The lengthy organ wait lists and deaths testify to the need to improve rates. A national debate should be initiated on whether to adopt a new societal paradigm in which organ donation is viewed as a civic responsibility, starting with introduction of the principle of presumed consent, in which all citizens are considered potential donors upon death, unless they've specified otherwise in advance. There's also a need to develop standard organ management practices and improve donation education programs for physicians and other frontline health care workers.

Clearly, structural reform is needed to achieve such objectives. To that end, the Conference of Deputy Ministers of Health should immediately place on their agenda a motion to reconstitute the existing Canadian Council for Donation and Transplantation as a national organ donation oversight agency, responsible for maintaining a national registry and allocation system. Simply handing over another \$I8 million over 5 years to a body whose advice and recommendations aren't binding won't solve the problems.

If the Council is disinterested, or unwilling to make such a transformation, then it should be disbanded and replaced with a body more responsive to the interests and needs of those who now patiently wait on organ donation lists. Equitable and fair access to an organ should no longer be accidental.

\section{Wayne Kondro}

News Editor, $C M A J$

Paul C. Hébert

Editor-in-Chief, $C M A J$

With the Editorial-Writing Team (Paul C. Hébert, Matthew Stanbrook, Barbara Sibbald, Ken Flegel, Noni MacDonald and Amir Attaran)

Ottawa, Ont. 